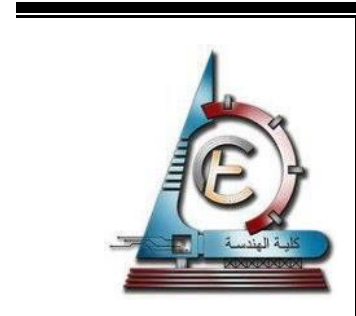

Journal of Engineering Sciences

Assiut University

Faculty of Engineering

Vol. 47

No. 1

January 2019

PP. 39-47

\title{
OPTIMIZATION OF THE ELECTROLESS NI-P COATING IN GLYCINE BATH BY TAGUCHI METHOD
}

\author{
Refaie Omar *, M. S. Aboraia, E. A. Oraby \\ Mining and Metallurgical Eng. Depart, Faculty of Engineering, Assiut University, Egypt. \\ Received 25 September 2018; Accepted 21 October 2018
}

\begin{abstract}
Electroless Ni-P coatings use in engineering applications due to its ability to alter and improve the surface properties of the steel substrate. The present study investigates the influence of bath composition, which included nickel sulphate, sodium hypophosphite, and glycine on the deposition rate, coating roughness, and final coating microhardness with using of Taguchi techniqe. The results reveal that final coating roughness and hardness can be optimized by controlling bath composition. The achieved minimum average surface roughness $(\mathrm{Ra})$ was $80.7 \mathrm{~nm}$ and the highest coating hardness was $1145 \mathrm{HV}$.
\end{abstract}

Keywords: Electroless plating, Surface roughness, Hardness, Taguchi Method.

\section{Introduction}

The ability to alter and develop the surface properties of the engineering parts is one of the most important goals to save maintenance cost and prolong parts service life. Protection of surfaces by coatings considered as a part of the design, development, and synthesis of novel and advanced engineering materials [1]. Ni-P amorphous alloy [2, 3] and Ni-P composites [4-7] deposits have wide acceptance to use for engineering applications such as chemical and mechanical industries due to their excellent surface properties.

Deposition of nickel from aqueous solution was first discovered by a chemical accident in 1844 by Wurtz [8]. The electroless plating process is an autocatalytic technique. In this process, cations of nickel reduced by electrons from the substrate which should be metal. The reductant is responsible for delivering these electrons to the surface and is thereby oxidized [9, 10]. The surface and final properties of electroless Ni-P coatings can be affected hugly by its composition and additives [11-16].

Electroless Ni-P plating bath content a source for the nickel ions, a reducing agent, and a complexing agent. In the present study, the nickel ions were introduced to bath by nickel sulphate, while electrons introduced by sodium hypophosphite as a reducing agent. Glycine was used as a complexing agent, to control free nickel ions in the bath and restrict reaction to start only on the substrate surface and inhibit the decomposition of the solution.

\footnotetext{
* Corresponding author.

E- mail address: eng_refaie2000@yahoo.com
} 
The present study aims to investigate the effect of solution composition on deposition thickness/rate, surface roughness, and hardness of the final surface with use of $L 9$ orthogonal array in Taguchi technique.

\section{Experimental details}

\subsection{Bath composition}

In the current study, the most important three parameters affecting the coating process chosen and varied with proper ranges after several trials and data in the literature [9, 17], while the other parameters were kept constant.

The following 3 factors (3 levels) affecting the electroless Ni-P coating were chosen: concentration of nickel sulphate (A), concentration of sodium hypophosphite (B), and the concentration of glycine $(\mathbf{C})$. The tree parameters were fitting in L9 orthogonal array (Taguchi analysis) by MINITAB -16 to minimize the number of experimental needed.

The bath composition variation as well as the operating conditions for electroless Ni-P coatings is presented in Table 1. All chemical used in the present research were obtained from Sigma-Aldrich, USA.

Table 1.

Electroless bath composition and operating conditions

\begin{tabular}{|c|c|c|c|c|}
\hline \multicolumn{4}{|c|}{ Bath Composition } & Operating Conditions \\
\hline Chemical Name & Formula & Function & Levels, $\mathrm{M}$ & \\
\cline { 1 - 4 } Nickel sulphate (A) & $\mathrm{NiSO}_{4}, 6 \mathrm{H}_{2} \mathrm{O}$ & Nickel source & $0.075,0.10,0.15$ & $\begin{array}{l}\text { pH } 5 \pm 0.2 \\
\text { Temperature, } 80 \pm 2^{\circ} \mathrm{C} \\
\text { Bath Volume, } 250 \mathrm{ml} \\
\text { Stirrer Speed, } 300 \mathrm{rpm} \\
\text { Deposition Time, } 1 \mathrm{~h} .\end{array}$ \\
\cline { 1 - 3 } Slycine (C) & $\mathrm{NaH}_{2} \mathrm{PO}_{2}$ & Reducing agent & $0.15,0.20,0.30$ & \\
\hline
\end{tabular}

\subsection{Sample preparation and coating}

Mild steel samples (12 $\mathrm{mm}$ in diameter and $6 \mathrm{~mm}$ height) were used for the plating process. Firstly, the surface was prepared by mechanical grinding up to 2400 grade by $\mathrm{SiC}$ papers and then polished up to $1 \mu \mathrm{m}$ diamond paste. Surface degreased with $10 \% \mathrm{NaOH}$ solution for $15 \mathrm{~min}$ at $60{ }^{\circ} \mathrm{C}$, cleaned in acetone by ultrasonic cleaning for $15 \mathrm{~min}$ and rinsed with deionized water after each step. Just before coating, the surface was activated by dipping in hydrochloric acid $(40$ vol. $\% \mathrm{HCl})$ for $30 \mathrm{~s}$. then the sample taken to the plating solution with $\mathrm{pH} 5$ and $80{ }^{\circ} \mathrm{C}$ temperature. The plating was done for $60 \mathrm{~min}$.

Magnetic stirrer using a $3 \mathrm{~cm}$ length PTFE coated magnetic paddle was used at $300 \mathrm{rpm}$ to ensure bath homogeneity during the experiment. After plating, the sample was taken out then thoroughly rinsed with deionized water and dry with nitrogen. Sodium hydroxide (1 M) was used as a $\mathrm{pH}$ regulator to adjust the bath $\mathrm{pH}$ every $20 \mathrm{~min}$.

\subsection{Coating evaluation}

For studying deposition rate (Dr), coating weight was determined by weighing each specimen before and after coating with a balance (0.01 $\mathrm{mg}$ accuracy) and the dimensions of the specimen was measured by a micrometer. The deposition rate (DR) was calculated according to Equation (1): 
Deposition rate $(\mathrm{Dr})=\frac{w 2-w 1}{\rho A t} \mu \mathrm{m} \mathrm{h}^{-1}$

Where: w1 and w2 are the weight of the specimen before and after coating respectively; $\rho$ is the density of coating, $A$ is the surface area of the specimen and $t$ is the coating time [18].

Surface profile for each sample was measured in different four directions by Alicona InfiniteFocus 3D microscopy and average surface roughness $(\mathrm{Ra})$ was calculated.

As heat treatment is known to increase the hardness of electroless nickel coatings [5, $19,20]$, the coated samples are heat treated in a tube furnace under an inert atmosphere for $1 \mathrm{~h}$ at $400^{\circ} \mathrm{C}$, then cooled in the air without application of any artificial cooling.

A MICROMET Microhardness tester was employed to measure the hardness of each coated sample with a load of $50 \mathrm{~g}$ and $20 \mathrm{~s}$ loading time. Ten indentations were carried out for each specimen; the average was used as the coating hardness HV according to ASTM E92 - 17.

\section{Results and discussion}

For all conducted experiments, analytical grade (AR) reagents and deionized water $(>17 \mathrm{M} \Omega . \mathrm{cm})$ were used. Thiourea was used as a stabilizer with a concentration of $1 \mathrm{mg} \mathrm{L}^{-}$ ${ }^{1}$ to prevent the plating bath from the uncontrolled breakdown [21, 22].

\subsection{Effect of bath composition on coating rate}

The validation of thickness calculations was confirmed by SEM cross-section imaging (Fig. 1) for the sample with a coating of $13 \mu \mathrm{m}$ thickness. The calculated thickness was $12.87 \mu \mathrm{m}$, this confirms that calculated thickness can be used reliably.

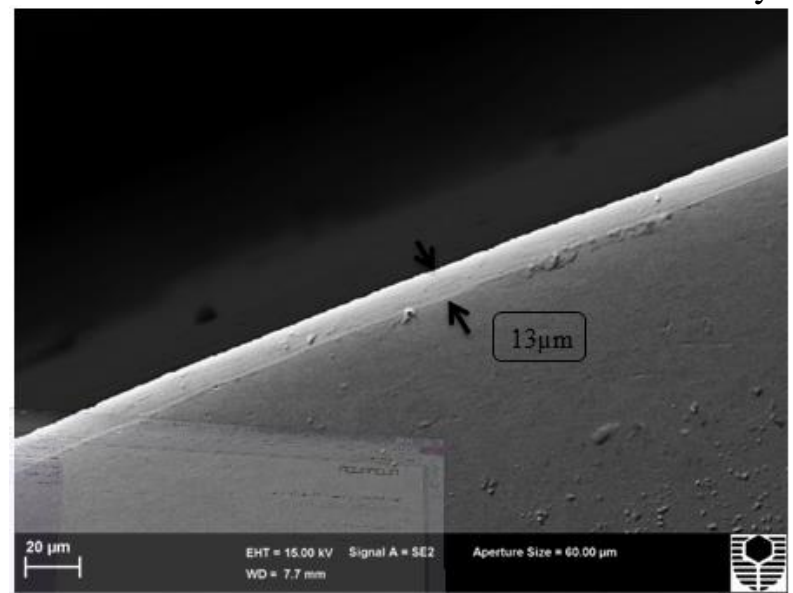

Fig. 1. Cross-section SEM confirms thickness calculations

The deposition rate of coating (Dr) was calculated for each sample and fitted with Taguchi orthogonal array L9. The Dr variation with each parameter is shown in Fig. 2. 


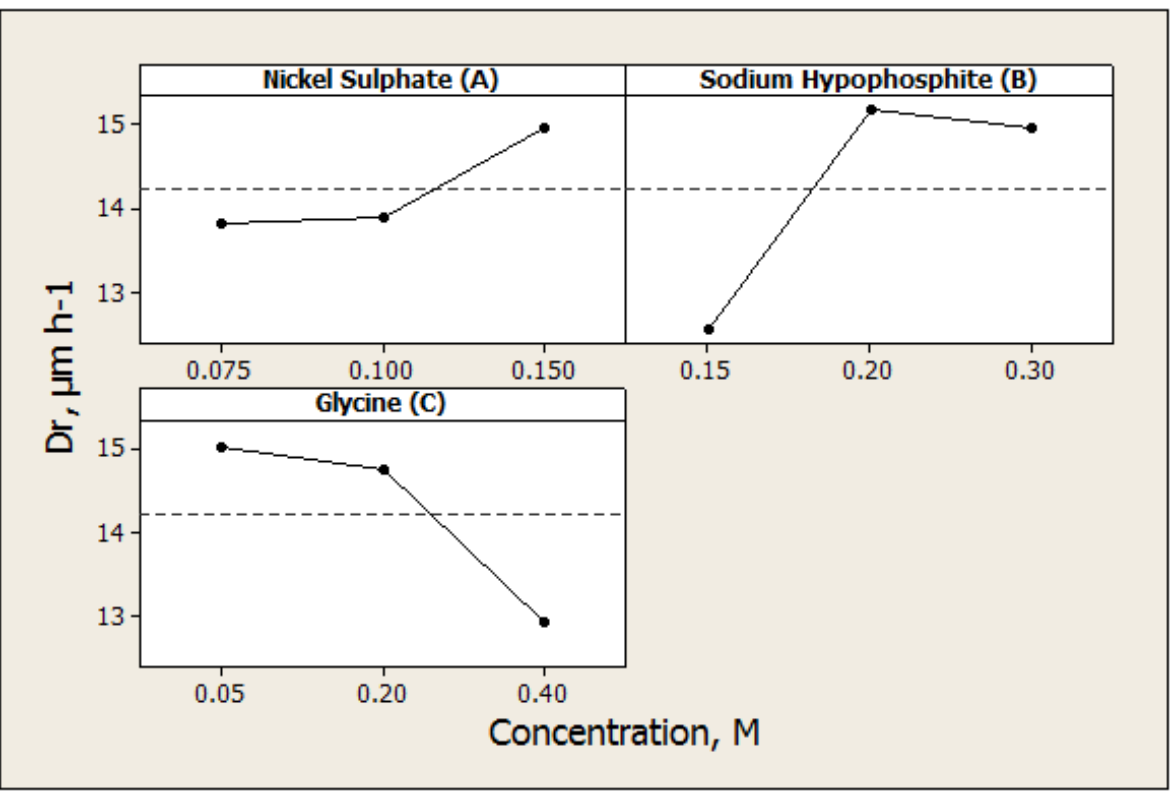

Fig. 2. Effect of bath composition on deposition rate (Dr) of the coating.

From Fig. 2 and Table 2, the nickel source (nickel sulphate) had a positive effect on the deposition rate, but such effect seems to be inattentive in compared to the effect of the reducing and complexing agents. From Table 2, the Delta value in Table 2 can be calculated by subtracting the smallest value from the biggest value for each parameter. It was used to rank the effect of each parameter on different response values. A greater Delta value represents the highest effect of the parameter (rank 1) [23]. The maximum Dr was achieved at hypophosphite concentration of $0.20 \mathrm{M}\left(15.18 \mu \mathrm{m} \mathrm{h}^{-1}\right)$. The reducing agent concentration controls the electrons availability in the bath which required reducing nickel ions according to the electrochemical mechanism introduced by Brenner and Riddell [10] which explain its remarkable effect on the DR. Also, the concentration of complexing agent (glycine) affects greatly the rate of plating. The last one controls the availability of free $\mathrm{Ni}^{+2}$ to be plated $[24,25]$.

Table 2.

Response of Dr

\begin{tabular}{|c|c|c|c|}
\hline Level & $\begin{array}{c}\text { Nickel sulphate } \\
(\mathbf{A})\end{array}$ & $\begin{array}{c}\text { Sodium hypophosphite } \\
(\mathbf{B})\end{array}$ & $\begin{array}{c}\text { Glycine } \\
(\mathbf{C})\end{array}$ \\
\hline 1 & 13.82 & 12.56 & 15 \\
\hline 2 & 13.91 & 15.18 & 14.75 \\
\hline 3 & 14.96 & 14.95 & 12.94 \\
\hline Delta & 1.14 & 2.62 & 2.06 \\
\hline Rank & 3 & 1 & 2 \\
\hline
\end{tabular}

\subsection{Effect of variables on surface roughness}

For surface roughness evaluation, the surface profile for each coated sample was measured, and average surface roughness $\mathrm{Ra}$ was calculated. The ability of each bath composition to change the surface roughness of final coating can be realized by showing the surface profile for each experimental set up as shown in Fig. 3. 


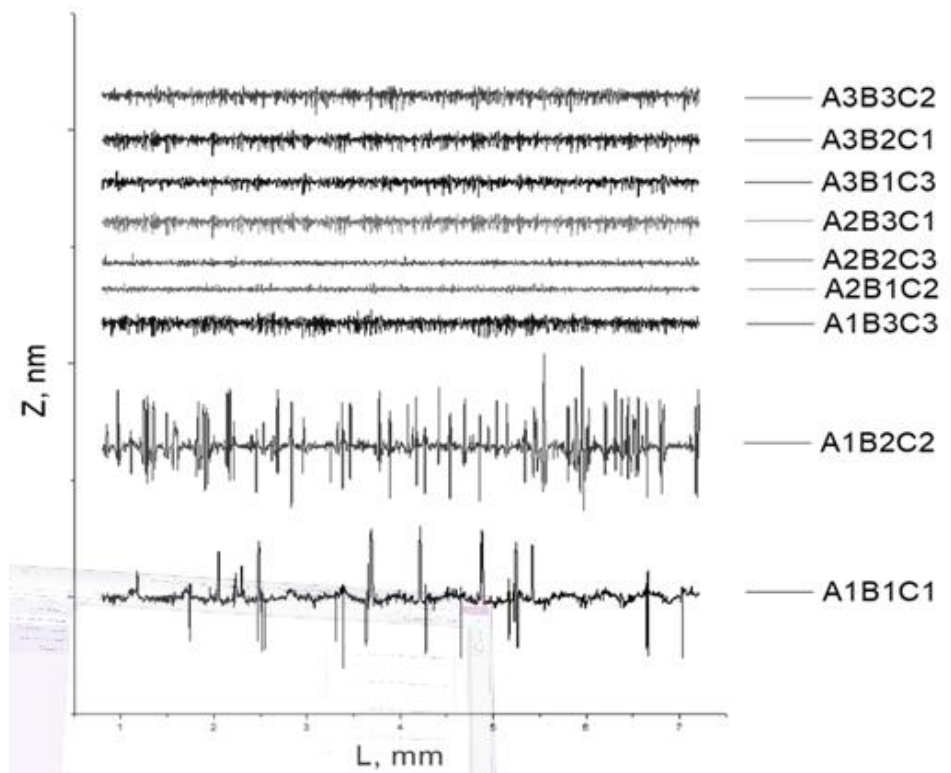

Fig. 3. Surface roughness profiles for the coated samples

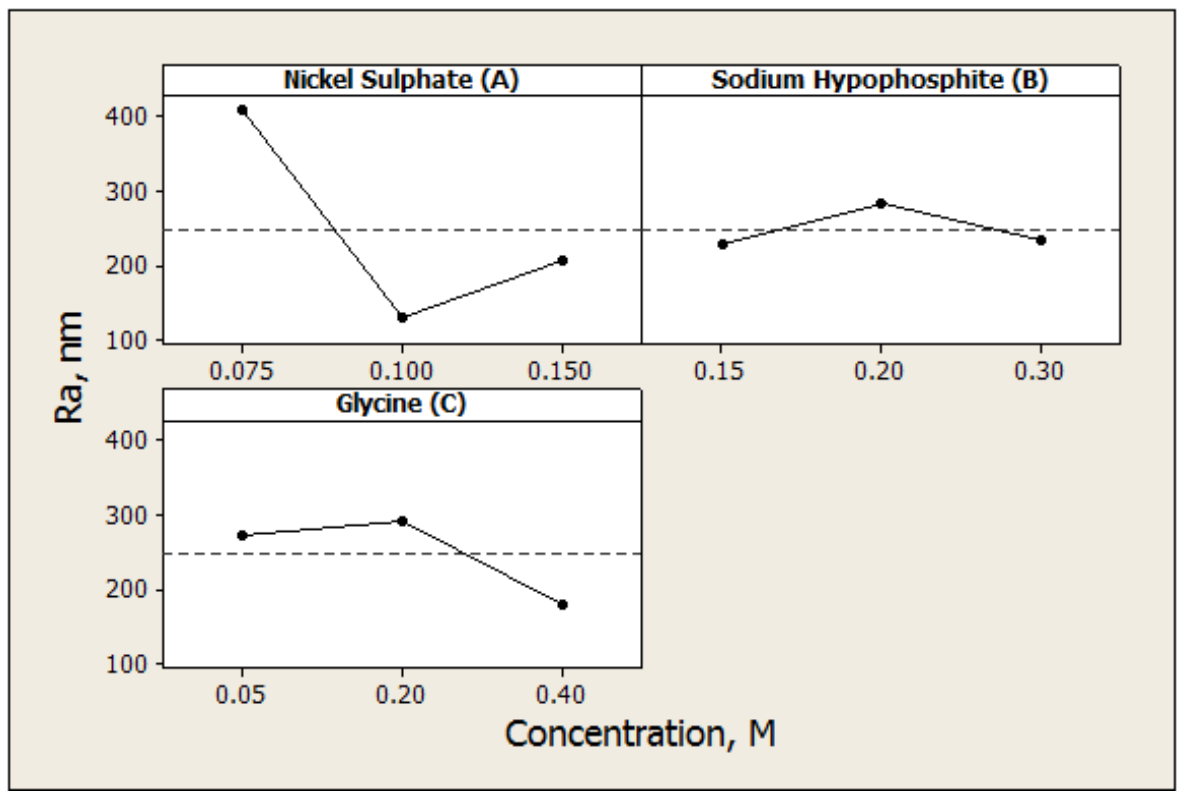

Fig. 4. Effect of bath composition on surface roughness $(\mathrm{Ra})$

Fig. 4 describes the effect of each constituent of plating bath on the final surface roughness. From Fig. 4, the nickel sulphate concentration (A) in the plating bath seems to have a positive effect on surface properties, as the samples surface change from rough to achieve the smoothest at concentration of A2. Also, the lowest roughness result from variation of hypophosphite was achieved at B1 as well as at glycine concentration $\mathrm{C} 3$ as in Fig. 3B and C. 
JES, Assiut University, Faculty of Engineering, Vol. 47, No. 1, January 2019, pp. 39-47

Table 3.

Response of $\mathrm{Ra}$

\begin{tabular}{|c|c|c|c|}
\hline Level & $\begin{array}{c}\text { Nickel sulphate } \\
(\mathrm{A})\end{array}$ & $\begin{array}{c}\text { Sodium hypophosphite } \\
(\mathrm{B})\end{array}$ & $\begin{array}{c}\text { Glycine } \\
(\mathrm{C})\end{array}$ \\
\hline 1 & 410 & 228.5 & 273.3 \\
\hline 2 & 128.7 & 283.6 & 291.8 \\
\hline 3 & 206.7 & 233.3 & 180.2 \\
\hline Delta & 281.3 & 55.1 & 111.6 \\
\hline Rank & 1 & 3 & 2 \\
\hline
\end{tabular}

According to the delta function, Table 3, the nickel sulphate concentration had the greatest effect on the coating surface roughness. The variation of sodium hypophosphite and glycine concentrations has the lowest effect on coating surface roughness.

\subsection{Effect of variables on hardness}

Improving surface hardness of engineering parts is one of the most important porpoises of applying Ni-P coating. To achieve the highest hardness from the coating layer, all the coated samples were exposure to a heat-treated process for 1 hour at $400{ }^{\circ} \mathrm{C}$. Heat treatment improves the hardness of coating due to change of the coating layer from amorphous to crystalline structure [26]. The effect of bath composition on the coating hardness is shown in Fig.5.

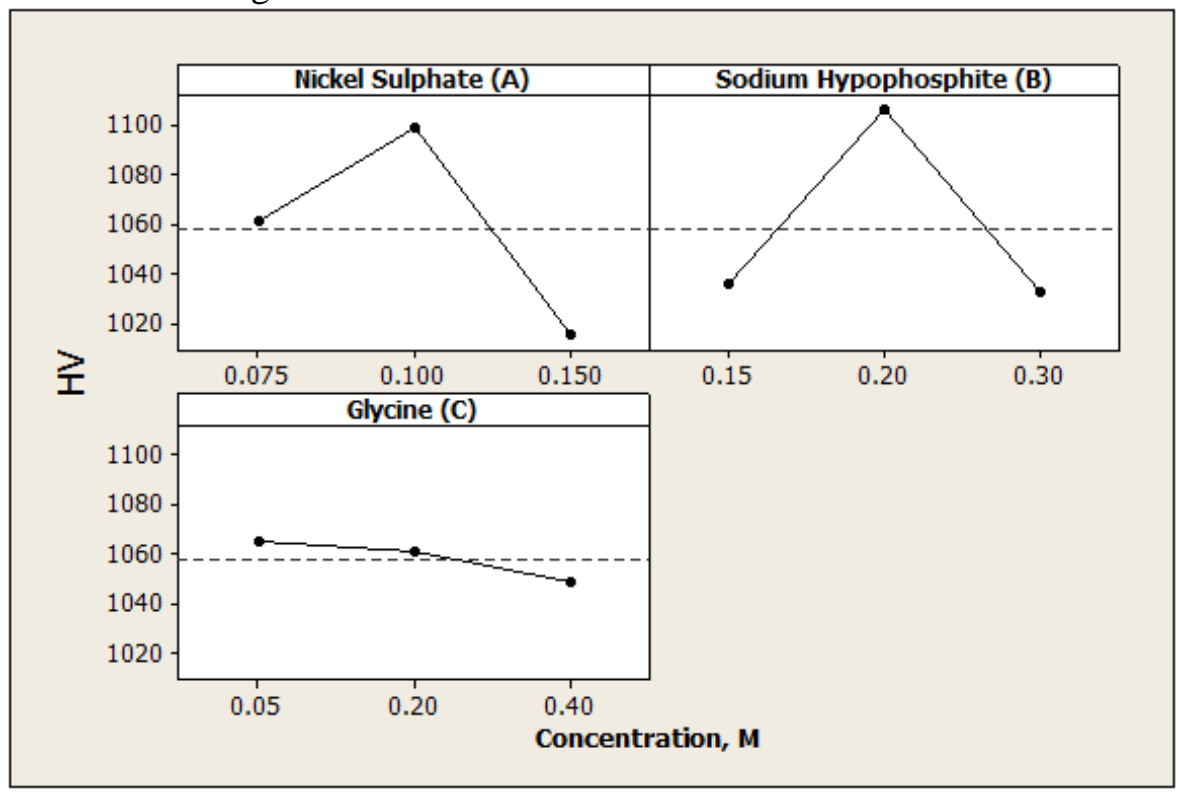

Fig. 5. Effect of bath composition on coating hardness (HV)

From Fig. 5, it is clear that the hardness of coating layer can by changed by changing of plating bath composition. Also, it can be noticed that the maximum hardness of coating (about $1100 \mathrm{HV}$ ) can be achieved at nickel sulphate with a concentration of A2. The hardness of coating also can be maximized up to $(1145 \mathrm{HV})$ by using sodium hypophosphite with a concentration of B2. The change of glycine concentration in the plating bath shows a minor effect on final coating hardness. 
Table 4.

Response of HV

\begin{tabular}{|c|c|c|c|}
\hline Level & $\begin{array}{c}\text { Nickel sulphate } \\
(\mathbf{A})\end{array}$ & $\begin{array}{c}\text { Sodium hypophosphite } \\
(\mathbf{B})\end{array}$ & $\begin{array}{c}\text { Glycine } \\
(\mathbf{C})\end{array}$ \\
\hline 1 & 1061 & 1036 & 1065 \\
\hline 2 & 1099 & 1106 & 1061 \\
\hline 3 & 1015 & 1032 & 1048 \\
\hline Delta & 84 & 74 & 17 \\
\hline Rank & 1 & 2 & 3 \\
\hline
\end{tabular}

From delta function in Table 4, the change of coating surface roughness can be considered first order depending on the concentration of nickel sulphate in the plating bath. Also, the lowest change in hardness can be observed with a change of glycine concentration.

\section{Conclusions}

The effect of Ni-P main plating bath composition on the final surface properties of the coated layer was investigated, and the results can be concluded as the following:

- Each parameter had a different effect on the deposition rate of coating, and the maximum deposition rate can be achieved from the plating bath contains A3B2C1.

- The coating surface roughness can be controlled by optimizing the nickel source, reducing agent, and complexing agent concentrations in the bath. Also, the smoothest surface was obtained at A2B1C3

- To gain maximum hardness from the coating, the plating bath with the composition of A2B2C1 is preferred.

\section{REFERENCES}

[1] León, C, García-Ochoa, E, García-Guerra, J and González-Sánchez, J, "Annealing temperature effect on the corrosion parameters of autocatalytically produced $\mathrm{Ni}-\mathrm{P}$ and $\mathrm{Ni}-\mathrm{P}-\mathrm{Al}_{2} \mathrm{O}_{3}$ coatings in artificial seawater." Surface and Coatings Technology, 205 (7) 2425-2431 (2010)

[2] Petukhov, I, Skryabina, N and Malinina, L, "Corrosion and Electrochemical Behavior of $\mathrm{Ni}-\mathrm{P}$ Coatings in $0.5 \mathrm{M} \mathrm{H}_{2} \mathrm{SO}_{4}$." Protection of metals, 38 (4) 370-376 (2002)

[3] Petukhov, IV, Medvedeva, NA, Subakova, IR and Kichigin, VI, "Corrosionelectrochemical behavior of Ni-P coatings in deaerated acidic sulfate solutions." Protection of Metals and Physical Chemistry of Surfaces, 50 (7) 875-882 (2014)

[4] Tseluikin, VN, "Composite electrochemical coatings: Preparation, structure, properties." Protection of Metals and Physical Chemistry of Surfaces, 45 (3) 312-326 (2009)

[5] Ivanov, M, "Electroless nickel-boron-phosphorus coatings: protective and functional properties." Protection of metals, 37 (6) 592-596 (2001)

[6] Kakareka, AS, Vrublevskaya, ON and Vorob'eva, TN, "Peculiarities of electroless deposition of Ni-W-P alloy on aluminum." Protection of Metals and Physical Chemistry of Surfaces, 49 (2) 222-228 (2013)

[7] Arslambekov, V, Loubnin, E, Ivanov, M, Drovosekov, A and Krutskikh, V, "The Kinetics and Mechanism of Thermal Oxidation of Electrolessly Deposited $\mathrm{Ni}-\mathrm{B}$ and $\mathrm{Ni}-\mathrm{W}-\mathrm{B}$ Alloys." Protection of metals, 40 (2) 153-158 (2004)

[8] Evans, P, Hendren, W, Atkinson, R, Wurtz, G, Dickson, W, Zayats, A and Pollard, R, "Growth and properties of gold and nickel nanorods in thin film alumina." Nanotechnology, 17 (23) 5746 (2006)

[9] Sudagar, J, Lian, J and Sha, W, "Electroless nickel, alloy, composite and nano coatings - A critical review." Journal of Alloys and Compounds, 571 183-204 (2013) 
[10] Brenner, A and Riddell, GE, "Nickel plating on steel by chemical reduction." J. Res. NBS, 37 (1) 31-34 (1946)

[11] Sotskaya, N, Ryabinina, E, Kravchenko, T and Shikhaliev, KS, "Kinetics of Electroless Plating of Ni-P Alloys with Organic Additives Containing-S-S-Fragments." Protection of metals, 39 (3) 250-254 (2003)

[12] Sotskaya, N, Ryabinina, E, Kravchenko, T and Shikhaliev, KS, "The role of organic additives in the electroless nickel plating bath." Protection of metals, 39 (3) 245-249 (2003)

[13] Hamdy, AS, Shoeib, MA, Hady, H and Abdel Salam, OF, "Corrosion behavior of electroless Ni-P alloy coatings containing tungsten or nano-scattered alumina composite in 3.5\% NaCl solution." Surface and Coatings Technology, 202 (1) 162-171 (2007)

[14] Szczygieł, B and Turkiewicz, A, "The effect of suspension bath composition on the composition, topography and structure of electrolessly deposited composite fourcomponent Ni-W-P-ZrO ${ }_{2}$ coatings." Applied Surface Science, 254 (22) 7410-7416 (2008)

[15] Krishnan, KH, John, S, Srinivasan, K, Praveen, J, Ganesan, M and Kavimani, P, "An overall aspect of electroless Ni-P depositions-a review article." Metallurgical and Materials Transactions A, 37 (6) 1917-1926 (2006)

[16] Brown, RJC, Brewer, PJ and Milton, MJT, "The physical and chemical properties of electroless nickel-phosphorus alloys and low reflectance nickel-phosphorus black surfaces." J. Mater. Chem., 12 (9) 2749-2754 (2002)

[17] Mallory, GO and Hajdu, JB, Electroless plating: fundamentals and applications. William Andrew, New York (US) (1990)

[18] Karthikeyan, S and Ramamoorthy, B, "Effect of reducing agent and nano Al2O3 particles on the properties of electroless Ni-P coating." Applied Surface Science, 307 654-660 (2014)

[19] Apachitei, I, Duszczyk, J, Katgerman, L and Overkamp, P, "Electroless Ni-P composite coatings: the effect of heat treatment on the microhardness of substrate and coating." Scripta Materialia, 38 (9) 1347-1353 (1998)

[20] Novák, M, Vojtěch, D and Vítů, T, "Influence of heat treatment on microstructure and adhesion of $\mathrm{Al} 2 \mathrm{O} 3$ fiber-reinforced electroless Ni-P coating on $\mathrm{Al}-\mathrm{Si}$ casting alloy." Materials Characterization, 61 (6) 668-673 (2010)

[21] Baskaran, I, Narayanan, TSNS and Stephen, A, "Effect of accelerators and stabilizers on the formation and characteristics of electroless Ni-P deposits." Materials Chemistry and Physics, 99 (1) 117-126 (2006)

[22] Cheong, W-J, Luan, BL and Shoesmith, DW, "Protective coating on Mg AZ91D alloy The effect of electroless nickel $(\mathrm{EN})$ bath stabilizers on corrosion behaviour of Ni-P deposit." Corrosion Science, 49 (4) 1777-1798 (2007)

[23] Park, I-C and Kim, S-J, "Cavitation erosion behavior in seawater of electroless Ni-P coating and process optimization using Taguchi method." Applied Surface Science, (2018)

[24] Huang, YS and Cui, FZ, "Effect of complexing agent on the morphology and microstructure of electroless deposited Ni-P alloy." Surface and Coatings Technology, 201 (9-11) 5416-5418 (2007)

[25] Wang, X-C, Cai, W-B, Wang, W-J, Liu, H-T and Yu, Z-Z, "Effects of ligands on electroless Ni-P alloy plating from alkaline citrate-ammonia solution." Surface and Coatings Technology, 168 (2-3) 300-306 (2003)

[26] Biswas, A, Das, SK and Sahoo, P, "Correlating tribological performance with phase transformation behavior for electroless Ni-(high)P coating." Surface and Coatings Technology, 328 102-114 (2017) 

الاستفادة المثلى من الطلاء اللاكهربى Ni-P باستخدام الجلايسين بطريقة تاجوتثى

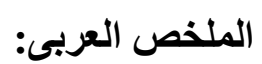

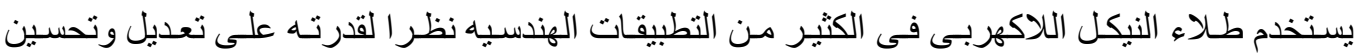

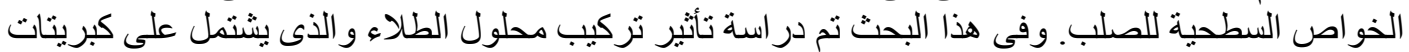

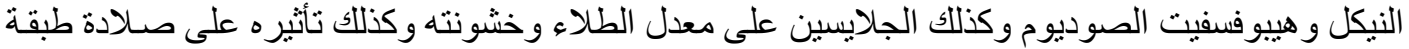

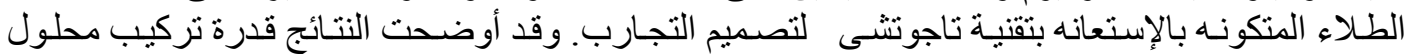

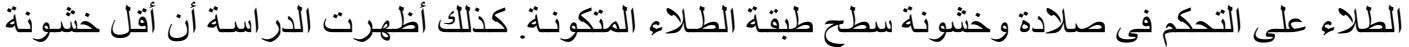
سطح أمكن الحصول عليها كانت 80.7 نانومنر وكنللك أقسى صلادة لسطح الطلاء كانت 1145 فيكرز. 